\title{
MAGHEMITE PARTICLES FOR SPERMIDINE SEPARATION
}

\author{
1,2Pavel KOPEL, 1,2Natalia CERNEI, 3Pavel HORKY, 1,2Zuzana LACKOVA, \\ 1,2Vedran MILOSAVLJEVIC, ${ }^{1,2}$ Milica GAGIC, ${ }^{1,2}$ Ondrej ZITKA, 1,2Vojtech ADAM \\ ${ }^{1}$ Department of Chemistry and Biochemistry, Faculty of AgriSciences, Mendel University in Brno, \\ Czech Republic, EU, vojtech.adam@mendelu.cz \\ ${ }^{2}$ Central European Institute of Technology, Brno University of Technology, Brno, Czech Republic, EU \\ ${ }^{3}$ Department of Animal Nutrition and Forage Production, Faculty of AgriSciences, Mendel University in Brno, \\ Czech Republic, EU
}

https://doi.org/10.37904/nanocon.2019.8496

\begin{abstract}
We report the optimal conditions for the separation of spermidine from different types of samples, for example blood or cancer cells and its subsequent determination by ion-exchange liquid chromatography (IEC) with UVVIS detector. Here in, we synthesized paramagnetic particles able to isolate and immobilize spermidine from blood of patients with cancer or cancer cells and thus preconcentrate it for analysis. Dowex surface was covered by nanomaghemite $\left(\mathrm{y}-\mathrm{Fe}_{2} \mathrm{O}_{3}\right)$ or maghemite particles surface was modified by chitosan and sulfoxyethyl cellulose. The best separation properties showed Dowex microparticles. The paramagnetic particles can be used in the future for isolation of spermidine from real samples and diagnosis of cancer.
\end{abstract}

Keywords: Ion exchange chromatography, maghemite, spermidine, chitosan and sulfoxyethyl cellulose

\section{INTRODUCTION}

Spermidine is a polyamine, usually isolated from sperm, located in the living cells, tissues and ribosomes [1]. Spermidine plays important role in various biological processes, such as regulation of plant growth, assisting in vitro process of transcribing RNA, and/or inhibition of nitric oxide synthase (NOS) [2]. Spermidine and spermine, are promising biomarkers of Parkinson disease (PD). Each polyamine enhance longevity via autophagy induction, under physiological conditions demonstrated ability of their metabolite to act as an diagnostic, age-related and severity of Parkinson disease [3]. On the other hand, increased levels of polyamines are toxic to cells, and can facilitate cell death based on the oxidative stress [4]. Polyamines, such as spermidine, spermine and putrescine have antioxidant properties, play major roles in the prevention of chronic diseases for example cardiovascular diseases and in the differentiation and development of immune system [5]. Currently, different methods are developed for spermidine detection. Most of them are based on chromatography (GC, HPLC) [6,7] with tandem of mass spectrometry (MS) [8], IEC [9] or CE [10]. In our study, we decided to use ion exchange chromatography with post-column ninhydrin derivatization and VIS detector for spermidine determination [10].

\section{METHODOLOGICAL BASES AND EXPERIMENTAL PART}

\subsection{Chemicals}

Spermidine of purity $99 \%$ was obtained from Sigma Aldrich (St. Louis, Missouri, USA). Solution of spermidine for preparing of calibration curve was prepared in the dilution buffer $\mathrm{Na}$ : TDG $\left(\mathrm{N}_{3} \mathrm{Na}-0.10 \mathrm{~g}, \mathrm{NaCl}-11.5 \mathrm{~g}\right.$, $\mathrm{C}_{6} \mathrm{H}_{8} \mathrm{O}_{7}-14 \mathrm{~g}$ per $1 \mathrm{~L} \mathrm{H} \mathrm{H}_{2} \mathrm{O}$ ). For experiment were used citric acid, $\mathrm{NaCl}, \mathrm{N}_{3} \mathrm{Na}$, TDG, $\mathrm{HCl} 35 \%$, ninhydrine, 
sulfoxyethyl cellulose, chitosan and Dowex from Sigma - Aldrich, Methylocelosolve (Ingos, Prague, Czech Republic), $\mathrm{SnCl}_{2}$ (Ingos, Prague, Czech Republic).

\subsection{Ionex chromatography}

An AAA 400 (Ingos, Czech Republic) liquid chromatography apparatus was used for determination of amino acids. The system consists of a glassy filling chromatographic column and steel precolumn, two chromatographic pumps for transport of elution buffers and derivatization reagent, cooled carousel for 25 test tubes of $1.5-2.0 \mathrm{~mL}$ volume, dosing valve, heat reactor, VIS detector and cooled chamber for derivatization reagent. Chromatographic columns for transfer of elution buffers and derivatization reagent are able to work at flow $0.01-10 \mathrm{~mL} \cdot \mathrm{min}^{-1}$ under a maximum pressure of $40 \mathrm{MPa}$. Volume of injected sample was $100 \mu \mathrm{L}$ with an accuracy of application RSD of about $1 \%$. A two-channel VIS detector with a $5 \mu \mathrm{L}$ flow volume cuvette was operated at wavelengths of 440 and $570 \mathrm{~nm}$.

\subsection{SEM characterization of PMPs}

Structures of particles were characterized by electron microscope MIRA 3 XMU (Tescan, a.s., Brno, Czech Republic). The SEM was fitted with Everhart-Thronley type of SE detector, high speed YAG scintillator based BSE detector, panchromatic CL Detector. For automated acquisition of selected areas, a TESCAN proprietary software tool called Image Snapper was used.

\subsection{Preparation of microparticles}

\section{MAN 1}

Iron chloride(III) hexahydrate $(2 \mathrm{~g})$ was dissolved in water $(160 \mathrm{~mL})$ and a solution of $\mathrm{NaBH}_{4}(0.4 \mathrm{~g})$ in $3.5 \%$ $\mathrm{NH}_{3}(20 \mathrm{~mL})$ was added with stirring. After hydrogen evolution, the mixture was heated to boiling for $2 \mathrm{~h}$ and left overnight. Nanomaghemite was separated on magnet and washed several times with water. Sulfoxyethyl cellulose $(0.5 \mathrm{~g})$ was poured into nanomaghemite suspension, agitated overnight, separated on external magnet and dried at $40^{\circ} \mathrm{C}$.

MAN 16

Nanomaghemite was prepared as described for MAN 1. Dowex $(1 \mathrm{~g})$ was poured to nanomaghemite suspension instead of cellulose.

MAN 25

In the preparation chitosan solution ( $1 \mathrm{ml}, 1 \%)$ was added with stirring to the suspension of nanomaghemite. Product was treated as in previous cases.

\section{RESULTS AND DISCUSSION}

Goal of our paper was primarily isolation and separation of spermidine, based on the adsorption of analyte on the paramagnetic microparticles and subsequent determination using ion-exchange liquid chromatography (IELC). We modified nanomaghemite with sulfoxyethyl cellulose (MAN 1), DOWEX (MAN 16) and chitosan (MAN 25). SEM characterization of the prepared microparticles is visualized of Figures 1 and 2. Paramagnetic particles on the surface of Dowex sphere are well seen on Figure 1A (MAN 16). The fibres of sulfoxyethyl cellulose covered with magnetic particles are visualized on Figure 1B and C for MAN 1, whereas the structure 
of MAN 15 is seen on Figure 2 at three different magnifications. All the three kinds of microparticles are stable in solution and are perfectly separated from the solution by external magnetic field. In our experiments of amines binding to paramagnetic particles, we have tested six amines. The results can be seen on graphs in Figure 3. These PMPs showed excellent properties for binding of spermidine (recovery $37.25 \%$ ) for MAN 16 , $15.6 \%$ for MAN 25 and $14.32 \%$ for MAN1 (Figure 3D). We used Britton-Robinson buffer with pH 2 which causes spermidine protonation that leads to positive charging of molecules due to its $\mathrm{pl}=5.3$ for spermidine. Interaction between surface of magnetic microparticles and positively charged molecules provides the binding between them. These interactions depend on isoelectric points of polyamines, which are in this mode behaving as the ion-exchangers.
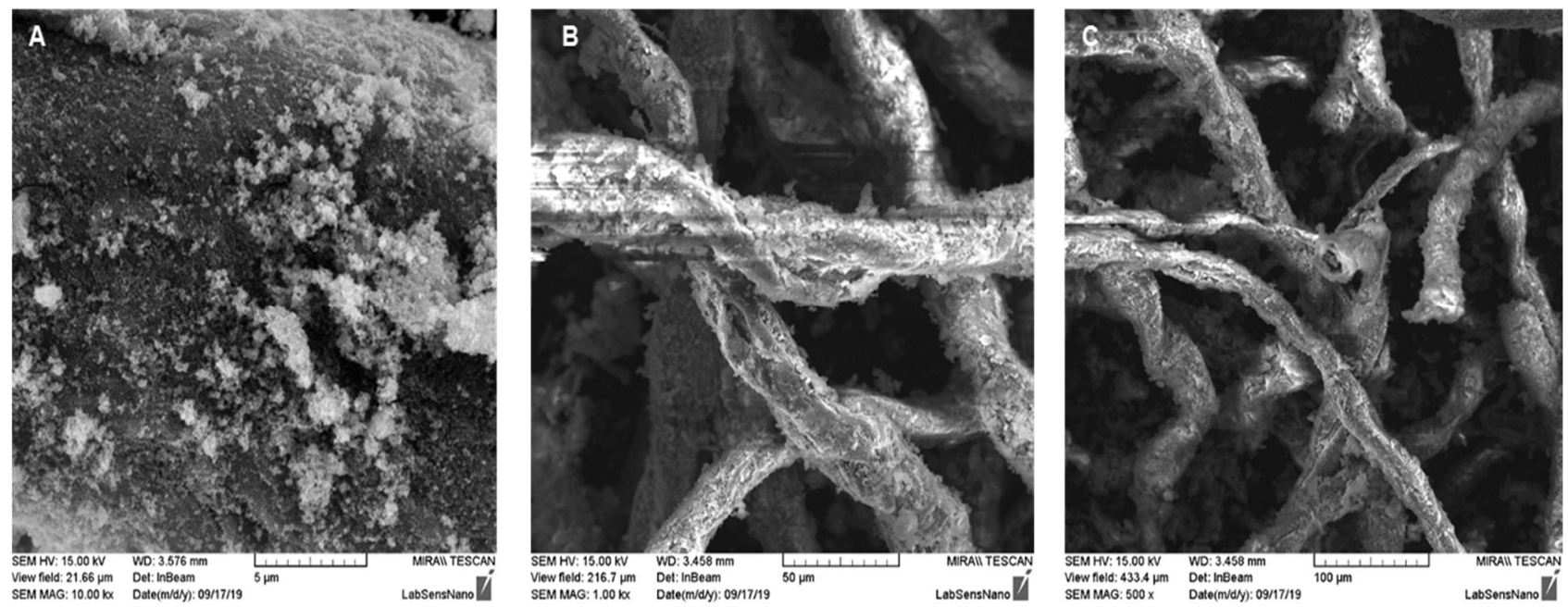

Figure 1 Characterization of paramagnetic particles. (A) SEM scan of paramagnetic microparticle MAN 16 in resolution of $5 \mu \mathrm{m}$, showing the particle size, (B) SEM scan of paramagnetic microparticle MAN 1 in resolution of $50 \mu \mathrm{m}$ and (C) SEM of MAN 1, scale $500 \mu \mathrm{m}$.
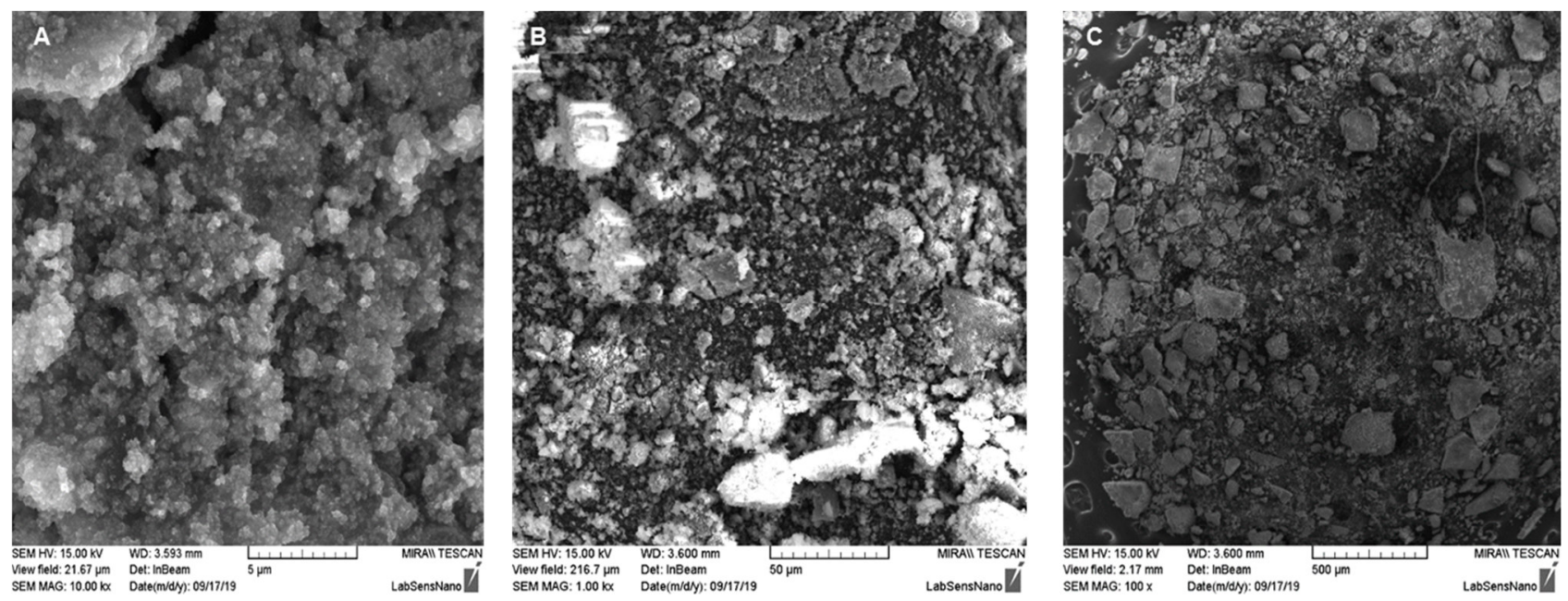

Figure 2 Characterization of paramagnetic particles MAN 25. (A) SEM scan of paramagnetic microparticles in resolution of $5 \mu \mathrm{m}$, showing the particle size. (B) SEM scan in resolution of $50 \mu \mathrm{m}$.

(C) $500 \mu \mathrm{m}$. 


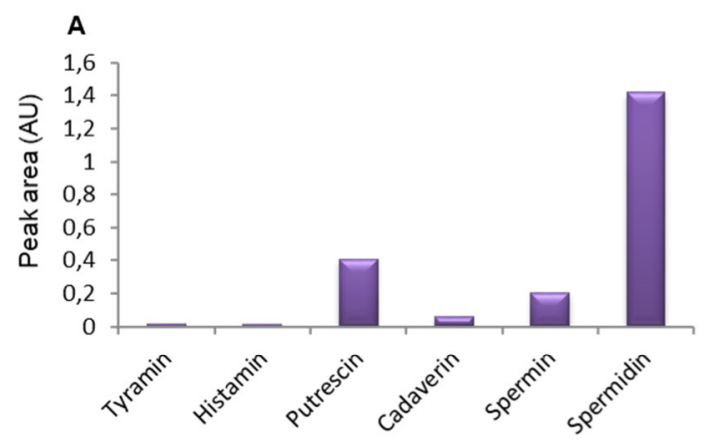

Analyte bound on PMPs

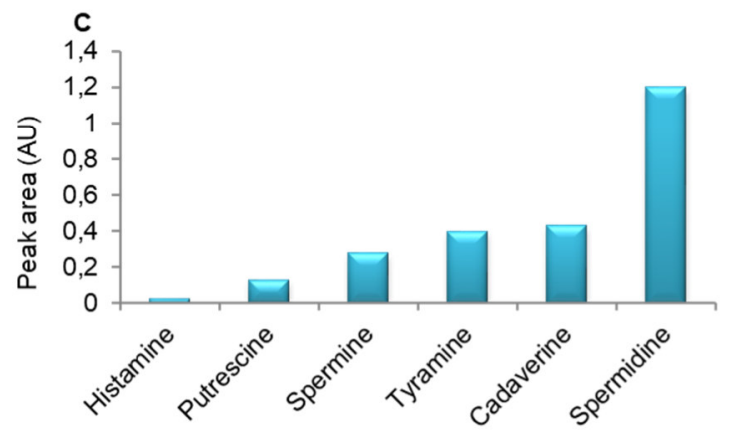

Analyte bound on PMPs

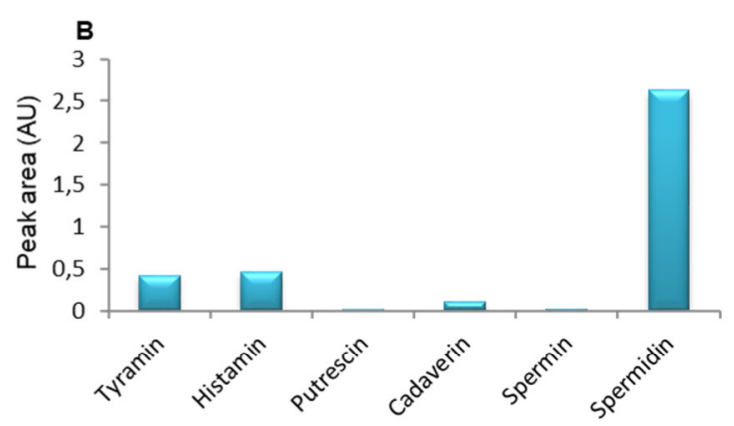

Analyte bound on PMPs

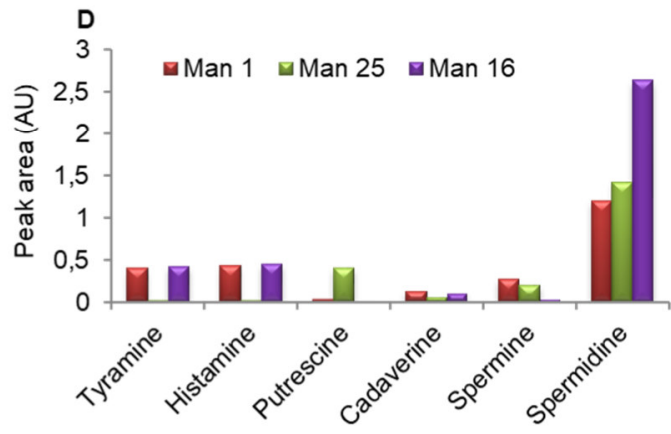

Analyte bound on PMPs

Figure 3 IELC characterization of paramagnetic particles (A) MAN 25, (B) MAN 16, (C) MAN 1, (D) IELC results showing ability of paramagnetic microparticles bound required substances specifically

\section{CONCLUSION}

In our study, we synthesized new paramagnetic microparticles able to bind spermidine that can be considered as promising biomarker of Parkinson disease. The paramagnetic microparticles (MAN 16) have potential to better isolation from the samples of plasma, cells and/or or tissue and in future can serve for application as a biosensor.

\section{ACKNOWLEDGEMENTS}

The financial support from NAZV QK1720349 and the Ministry of Education, Youth and Sports of the Czech Republic under the project CEITEC 2020 (LQ1601) is highly acknowledged.

\section{REFERENCES}

[1] MINOIS, Nadege. Molecular basis of the 'anti-aging' effect of spermidine and other natural polyamines - a minireview. Gerontology. 2014. vol. 60, pp. 319-326.

[2] ANDERSEN, S.C., BASTOLA, D.R. and MINOCHA, S.C. Metabolism of polyamines in transgenic cells of carrot expressing a mouse ornithine decarboxylase cdna. Plant Physiol. 1998. vol. 116, pp. 299-307.

[3] SAIKI, Shinji, SASAZAWA, Yukiko, FUJIMAKI, Motoki, KAMAGATA, Koji, KAGA, Naoko, TAKA, Hikari, LI, Yuanzhe, Z., SOUMA, Sanae, HATANO, Taku, IMAMICHI, Yoko et al. A metabolic profile of polyamines in parkinson disease: A promising biomarker. Ann. Neurol. 2019. vol. 86, pp. 251-263. 
[4] TIL, H.P., FALKE, H.E., PRINSEN, M.K. and WILEMS, M.I. Acute and subacute toxicity of tyramine, spermidine, spermine, putrescine and cadaverine in rats. Food Chem Toxicol. 1997. vol. 35, pp. 337-348.

[5] MUNOZ-ESPARZA, Nelly C., LATORRE-MORATALLA, Luz M., COMAS-BASTE, Oriol, TORO-FUNES, Natalia, VECIANA-NOGUES, Teresa M. and VIDAL-CAROU, Carmen M. Polyamines in food. Front. Nutr. 2019. vol. 6, 108.

[6] PETRARCA, Mateus H., FERNANDES, Jose O., GODOY, Helena T., CUNHA and Sara C. Determination of polyamines in baby food by gas chromatography-mass spectrometry: Optimization of extraction and microwaveassisted derivatization using response surface methodology. Food Anal. Meth.2017. vol. 10, pp. 3548-3557.

[7] BRANDSTETEROVA, E., HATRIK, S., BLANARIK, I. and MARCINCINOVA, K. HPLC determination of polyamines in urine. Neoplasma. 1991. vol. 38, pp. 165-174.

[8] ONAL, Armagan, TEKKELI, Serife E.K. and ONAL, Cem. A review of the liquid chromatographic methods for the determination of biogenic amines in foods. Food Chem. 2013, vol, 138, pp. 509-515.

[9] CERNEI, Natalia, HEGER, Zbynek, KOPEL, Pavel, SKLADANKA, Jiri, ZITKA, Ondrej, ADAM, Vojtech and KIZEK, Rene. Isolation of biogenic amines using paramagnetic microparticles off-line coupled with ion exchange liquid chromatography. Chromatographia. 2014. vol. 77, pp. 1451-1459.

[10] DANIEL, Daniela, dos SANTOS, Vagner B., VIDAL, Rajh D.T. and do LAGO, Claudimir L. Determination of biogenic amines in beer and wine by capillary electrophoresis-tandem mass spectrometry. J. Chromatogr. A. 2015. vol. 1416, pp. 121-128. 